\title{
真心による管理
}

Stakeholder Equity

\begin{abstract}
Pay inequality, tax avoidance, abuse of superior bargaining power, pollution... the list of corporate misdeeds seems to keep growing. No company wants to be labelled as being guilty of any of these practices. Therefore some mention of corporate social responsibility has become de rigueur in corporate annual reports. But short of making high sounding declarations how can a company show that its practices have been fair and socially responsible? This article starts with the premise that society, employees, suppliers, creditors and shareholders have a collective stake in the wellbeing of the company, and that the company's performance should be judged by its returns to all stakeholders. This view contrasts with the usual shareholder centric measurements of corporate performance. Traditional metrics might provide the answers sought by one or another class of stakeholders, but they do not address the question of whether the maximisation of returns to one class of stakeholders might be at the expense of another. This article demonstrates that it is feasible, by using information that is available in a corporation's annual report, and in particular information in its financial statements, to measure corporate performance that maximises returns to all stakeholders.
\end{abstract}




\section{Accounting For Growth}

Author: Kok Choy LOH

\section{Rita no Kokoro 利他の心}

"No company can generate long-term profit unless it makes every stakeholder happy." Kyocera Founder Kazuo Inamori

When he founded his first company, Kyocera, in 1959, Kazuo Inamori searched for a corporate philosophy that would guide how Kyocera would be managed. He called the philosophy he developed Rita no Kokoro. Today, Rita no Kokoro is still the guiding philosophy of Kyocera, an electronics giant with a turnover of $¥ 1.5$ trillion. In 1984, Inamori founded the telecommunication company, Daini-Denden, adhering to his philosophy of Rita no Kokoro. Daini-Denden became today’s $¥ 4.5$ trillion KDDI. And in 2010, he responded to the government's call and, applying the philosophy of Rita no Kokoro, rescued Japan Airlines from bankruptcy, turning in a profit one year later.

So what is Inamori's corporate philosophy? The following quotes, taken from his June 2015 lecture at Ritsumeikan University, Osaka, shed some light on Rita no Kokoro. [Inamori, 2015]

On Society: "... I feared an adverse impact of the failure of JAL on the Japanese economy... If this company failed... the damage to the Japanese economy could have been enormous... In short, it is Rita no Kokoro: a drive to contribute to the good of society and people... that made me decide to take up the responsibility to reconstruct JAL..."

On Employees: “... I was led to the realization that the most important goal of corporate management is to ensure the wellbeing of employees...Therefore, I set the goal of providing opportunities for the material and intellectual growth of all our employees as part of the management philosophy of our company. But this goal alone seemed not meaningful enough for us to pursue, so I supplemented the philosophy by adding another goal, contributing to the advancement of society and humankind..."

On Customers: "...I repeatedly visited airports myself, where I spoke to JAL employees who directly served customers and said to them, "... do your utmost to serve customers with warm hospitality. Doing so will certainly lead JAL to a bright future."

On Shareholders: “... To some, the purpose of providing opportunities for the material and intellectual growth of all employees may seem to be contradictory to the interests of shareholders... However, I believe that employees who work diligently for their company in pursuit of their material and intellectual growth can better contribute to enhancing corporate performance, which will eventually result in greater benefits for shareholders. On the contrary, if a company shortsightedly seeks to serve the interests of its shareholders without consideration for its employees, then the company will face difficulties in the long run leading to negative consequences for its shareholders..."

On Business Partners: “... As I emphasized when speaking about my experience with the management of KDDI and JAL, we can earn the trust and respect of our customers, shareholders, business partners and agencies they do business with by running a company based on the principle of Rita no Kokoro to contribute to the good of society and people. In this way, all stakeholders will support us and help us achieve success in business..." 


\section{What Is Accounting For Growth?}

The concept of Accounting For Growth initially may seem strange, especially to someone who is accustomed to thinking solely in terms of shareholders' returns. That is because Accounting For Growth measures the aggregate returns on stakeholder contributions.

Accounting For Growth (AFG) tells us how much of a company's growth derives from increases in the resources (i.e. stakeholders' contributions) that a company consumes. The company's ability to optimise the mix of resources it deploys is a critical driver of growth.

Accounting For Growth takes into account how stakeholders are rewarded relative to stakeholders' contributions to a company's growth. In other words Accounting For Growth is stakeholder centric rather than being narrowly shareholder centric.

By evaluating the effect of a change in the composition of resources (i.e. a change in stakeholders' inputs) that a company consumes, Accounting For Growth helps answer questions such as: Should the company outsource or should it keep a task in-house? Should the company make or should the company buy? Has the company's overall performance been good, or bad?

Take for example the case of Marks \& Spencer in 2016. [Marks And Spencer, 2016] Revenue grew by $2.366 \%$ compared to 2015 . Increases in resources accounted for, at most, $1.224 \%$ of growth. That is, M\&S's actual growth in 2016 was $1.142 \%$ greater than expected growth. Overall, M\&S performed creditably in 2016. The company was able to extract the maximum revenue given the composition of its resources that year.

Could the company have done better? That depends on whether the company had the ability to improve on the composition of its resources. For example, if the company currently outsources a particular task at the cost of $£ 20$ million per year, the company might improve its resource utilisation if it could take the task in-house by employing 355 more workers and investing $£ 5$ million in equipment with an average lifespan of 10 years.

However, the company would not take a task in-house, even though profits to shareholders would increase, if the company currently outsources the task at the cost of $£ 20$ million per year but will require investments in new assets costing $£ 15$ million and recruitment of 700 more employees.

How do we arrive at these answers? Accounting For Growth provides a methodology that answers questions such as those. Answers that stakeholders might find helpful.

Who are stakeholders? What might they want of the company? Shareholders want high returns. Creditors seek assurance about the company's creditworthiness. Employees hope their career would grow with the company. Suppliers want continuing business. And society expects that the company pays its dues and that it does not pollute the environment.

Although they want different outcome of the company, all stakeholders share a common stake in the wellbeing of the company. Traditional metrics might provide the answers sought by one or another class of stakeholders, but they do not address the question of whether the maximisation of returns to one class of stakeholders might be at the expense of another. Accounting For Growth offers a comprehensive metric that measures whether a company's growth in revenue has been achieved through an 
efficient combination of the contributions by, and the equitable returns to, all its stakeholders.

Do the computations of these numbers interest the company's stakeholders? Is the information about a company's ability to optimise the resources it deploys relevant to investment analysts and credit rating agencies? Is there any reason, if banks and investment funds have access to easy tools to arrive at the answers, that these financial institutions wouldn't want to use them? How do we measure whether a company lives up to its claims regarding its corporate social responsibility?

Whereas ROE measures the returns on shareholders' equity and ROCE measures the returns on both shareholders' and creditors' funding, Accounting For Growth measures the returns on all resources employed, including but not limited to only capital. In other words, Accounting For Growth measures returns to all stakeholders.

The mathematics used in Accounting For Growth is not as simple as that used in, say, returns on capital employed (ROCE). Complicated mathematics is definitely a disadvantage, but complicated mathematics should not deter us from using Accounting For Growth if it provides additional insights into the performance of a company. After all, we often calculate the probabilities and standard deviations of normal (bell curve) distributions even though the formula for normal distribution is also quite complex.

The formula for normal (bell curve) distribution is

$$
f\left(x \mid \mu, \sigma^{2}\right)=\frac{1}{\sqrt{2 \pi \sigma^{2}}} e^{-\frac{(x-\mu)^{2}}{2 \sigma^{2}}}
$$

Despite its complex formula normal distribution is part of our daily analytical repertoire. Why? Because we simply rely on the computer to do the heavy calculations. All that is expected of us is that we understand the concepts underlying a normal distribution. And so it is with Accounting For Growth.

\section{Re-arranging The Balance Sheet And Income Statement}

Accounting For Growth is best undertaken using the company's internal data. However, if access to the company's internal records is not available, one could nonetheless make a good estimate of the data needed for Accounting For Growth. One could use the published financial statements, provided that one carefully reads also the notes to the financial statements.

In Accounting For Growth we start by determining the changes in the company's input structure (input structure will be discussed in the next section). However, before we determine how the input structure has changed, we must re-arrange the balance sheet and the income statement. So I reproduce below the M\&S 2016 balance sheet and income statement as they are presented in the company's annual report. These same statements are then shown rearranged.

Fig 1 is the balance sheet taken from M\&S’s 2016 Annual Report. [Marks And Spencer, 2016]

Fig 2 is the Income Statement, also taken from M\&S's 2016 Annual Report. [Marks And Spencer, 2016] 
CONSOLIDATED STATEMENT OF FINANCIAL POSITION

\begin{tabular}{|c|c|c|c|}
\hline & Notes & $\begin{array}{r}\text { As at } \\
2 \text { April } 2016 \\
\mathrm{fm}\end{array}$ & $\begin{array}{r}\text { Asat } \\
28 \mathrm{March} 2015 \\
\mathrm{fm} \\
\end{array}$ \\
\hline \multicolumn{4}{|l|}{ Assets } \\
\hline \multicolumn{4}{|l|}{ Non-current assets } \\
\hline Intangible assets & 14 & 802.8 & 858.2 \\
\hline Property, plant and equipment & 15 & $5,027.1$ & $5,031.1$ \\
\hline Investment property & & 15.5 & 15.6 \\
\hline Investment in joint ventures & & 6.9 & 12.2 \\
\hline Other financial assets & 16 & 3.0 & 3.0 \\
\hline Retirement benefit asset & 11 & 851.0 & 460.7 \\
\hline Trade and other receivables & 17 & 234.7 & 283.3 \\
\hline Derivative financial instruments & 21 & 74.0 & 75.8 \\
\hline \multirow[t]{2}{*}{ Deferred taxassets } & 23 & - & 1.2 \\
\hline & & $7,015.0$ & $6,741.1$ \\
\hline \multicolumn{4}{|l|}{ Current assets } \\
\hline Inventories & & 799.9 & 7978 \\
\hline Other financial assets & 16 & 19.1 & 11.6 \\
\hline Trade and other receivables & 17 & 321.1 & 321.8 \\
\hline Derivative financial instruments & 21 & 72.1 & 117.9 \\
\hline Current taxassets & & 1.6 & - \\
\hline \multirow[t]{2}{*}{ Cash and cash equivalents } & 18 & 247.6 & 205.9 \\
\hline & & $1,461.4$ & $1,455.0$ \\
\hline Total assets & & $8,476.4$ & $8,196.1$ \\
\hline \multicolumn{4}{|l|}{ Liabilities } \\
\hline \multicolumn{4}{|l|}{ Current liabilities } \\
\hline Trade and other payables & 19 & $1,617.7$ & $1,642.4$ \\
\hline Partnership liability to the Marks \& Spencer UK Pension Scheme & 12 & 71.9 & 71.9 \\
\hline Borrowings and other financial liabilities & 20 & 297.5 & 279.4 \\
\hline Derivative financial instruments & 21 & 28.5 & 7.7 \\
\hline Provisions & 22 & 14.0 & 46.2 \\
\hline \multirow[t]{2}{*}{ Current tax liabilities } & & 75.2 & 64.0 \\
\hline & & $2,104.8$ & $2,111.6$ \\
\hline \multicolumn{4}{|l|}{ Non-current liabilities } \\
\hline Retirement benefit deficit & 11 & 26.9 & 1117 \\
\hline Trade and other payables & 19 & 353.0 & 319.7 \\
\hline Partnership liability to the Marks \& Spencer UK Pension Scheme & 12 & 383.8 & 441.0 \\
\hline Borrowings and other financial liabilities & 20 & $1,774.7$ & $1,745.9$ \\
\hline Derivative financial instruments & 21 & 0.2 & 20.0 \\
\hline Provisions & 22 & 52.0 & 32.1 \\
\hline \multirow[t]{2}{*}{ Deferred tax liabilities } & 23 & 337.6 & 315.3 \\
\hline & & $2,928.2$ & $2,885.7$ \\
\hline Total liabilities & & $5,033.0$ & $4,997.3$ \\
\hline Net assets & & 3,443.4 & $3,198.8$ \\
\hline \multicolumn{4}{|l|}{ Equity } \\
\hline Issued share capital & 24 & 405.8 & 412.0 \\
\hline Share premiumaccount & & 411.3 & 392.4 \\
\hline Capital redemption reserve & & $2,210.5$ & $2,202.6$ \\
\hline Hedging reserve & & 32.3 & 64.3 \\
\hline Other reserve & & $(6,542.2)$ & $(6,542.2)$ \\
\hline Retained earnings & & $6,927.5$ & $6,670.5$ \\
\hline Total shareholders' equity & & $3,445.2$ & $3,199.6$ \\
\hline Non-controlling interests in equity & & (1.8) & $(0.8)$ \\
\hline Total equity & & $3,443.4$ & $3,198.8$ \\
\hline
\end{tabular}

Fig 1 
86

FINANCPELNER CROUP PLC

CONSOLIDATED INCOME STATEMENT

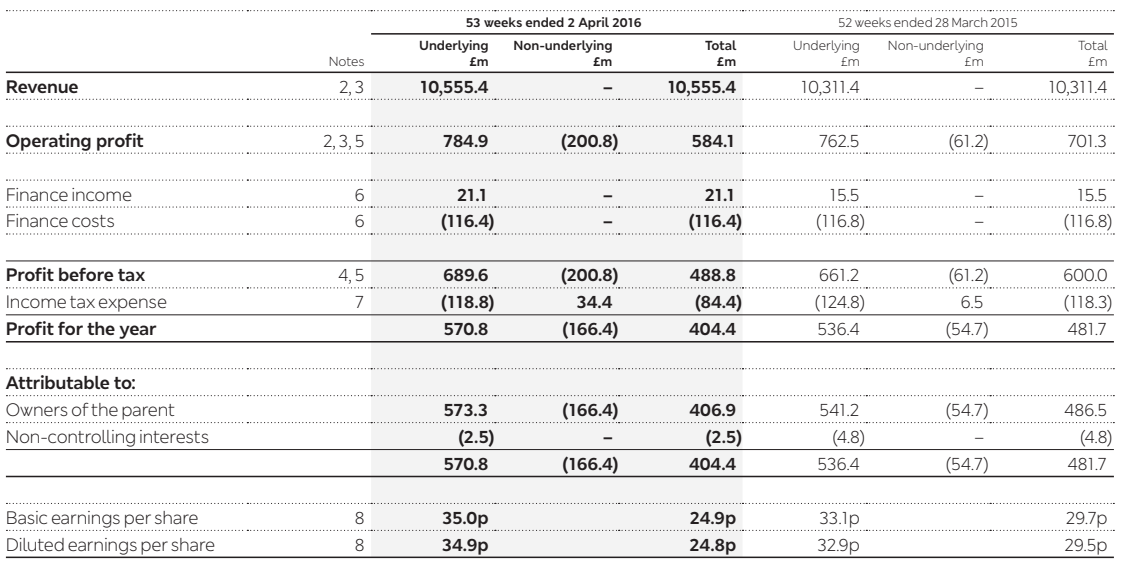

CONSOLIDATED STATEMENT OF COMPREHENSIVE INCOME

\begin{tabular}{|c|c|c|c|}
\hline & & $\begin{array}{l}53 \text { weeks ended } \\
2 \text { April } 2016\end{array}$ & $\begin{array}{l}52 \text { weeks ended } \\
28 \text { March } 2015\end{array}$ \\
\hline & Notes & & \\
\hline Profit for the year & & 404.4 & 481.7 \\
\hline \multicolumn{4}{|l|}{ Other comprehensive income: } \\
\hline \multicolumn{4}{|l|}{ Items that will not be reclassified to profit or loss } \\
\hline Remeasurements of retirement benefit schemes & 11 & 346.2 & 193.7 \\
\hline \multirow[t]{2}{*}{ Tax charge on items that will not be reclassified } & & (45.6) & $(40.2)$ \\
\hline & & 300.6 & 153.5 \\
\hline \multicolumn{4}{|l|}{ Items that will be reclassified subsequently to profit or loss } \\
\hline Foreign currency translation differences & & 7.3 & (7.5) \\
\hline \multicolumn{4}{|l|}{ Cash flow hedges and net investment hedges } \\
\hline - fair value movements recognised in other comprehensive income & & (30.1) & 221.2 \\
\hline - reclassified and reported in profit or loss & & (22.1) & $(60.0)$ \\
\hline -amount recognised in inventories & & 5.9 & (21.6) \\
\hline \multirow[t]{2}{*}{ Tax credit/(charge) on cash flow hedges and net investment hedges } & & 6.5 & (21.2) \\
\hline & & (32.5) & 110.9 \\
\hline Other comprehensive income for the year, net of tax & & 268.1 & 264.4 \\
\hline Total comprehensive income for the year & & 672.5 & 746.1 \\
\hline \multicolumn{4}{|l|}{ Attributable to: } \\
\hline Owners of the parent & & 675.0 & 750.9 \\
\hline \multirow[t]{2}{*}{ Non-controlling interests } & & (2.5) & $(4.8)$ \\
\hline & & 672.5 & 746.1 \\
\hline
\end{tabular}

Fig 2 
Fig 3 shows the same balance sheet for 2016 but re-arranged. A balance sheet must, well, balance. That means if we group all non-financial assets, the sum of these nonfinancial assets should equal the sum of all financial liabilities (including equity) less all financial assets. The total of all non-financial assets as at 1 st April 2016 was $£ 6,629.8$ million, which of course equals the net total of financial liabilities less financial assets.

Fig 4 shows the non-financial assets for 2015, 2016 and 2017. [Marks And Spencer, 2015] [Marks And Spencer, 2016] [Marks And Spencer, 2017]

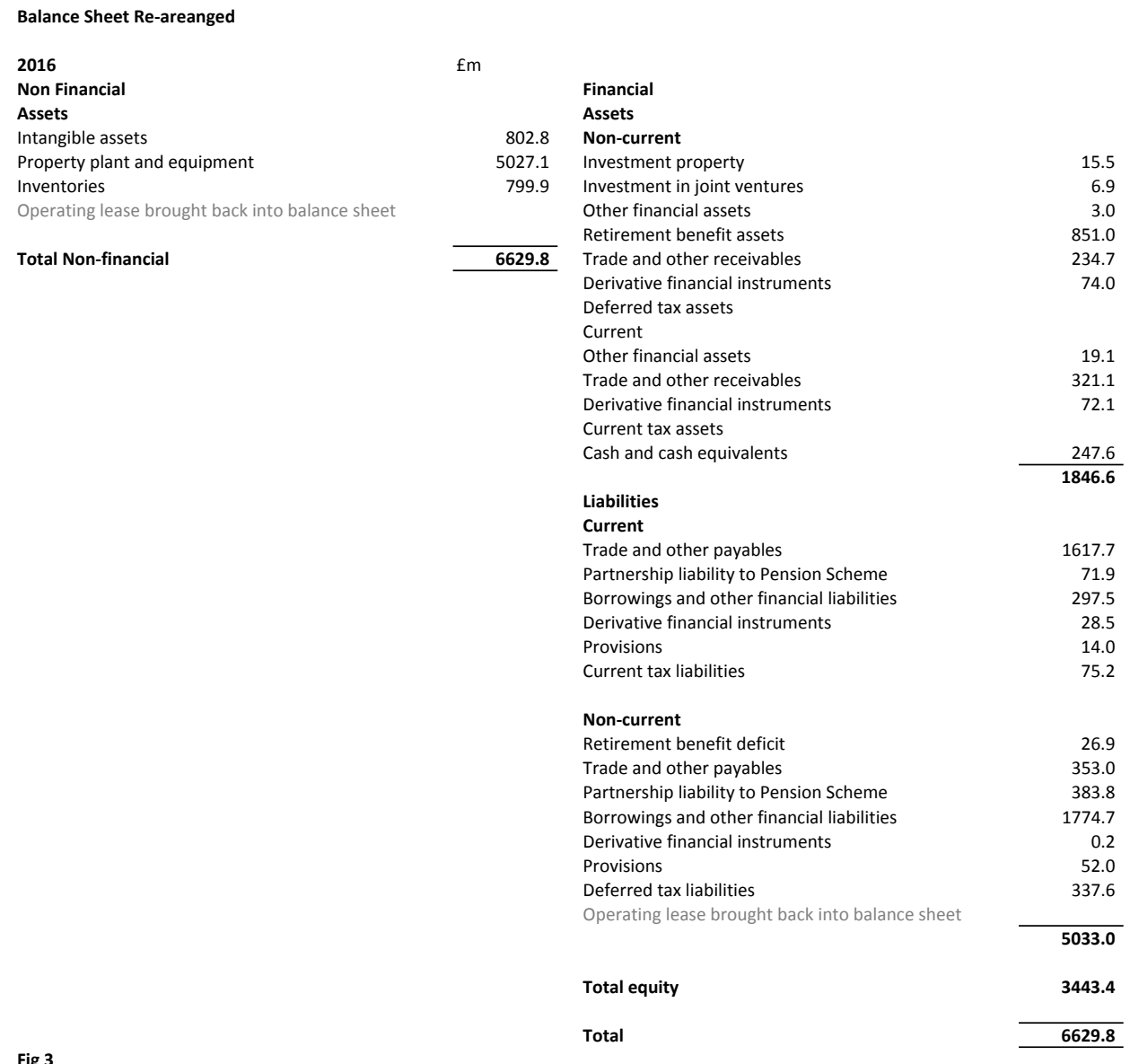




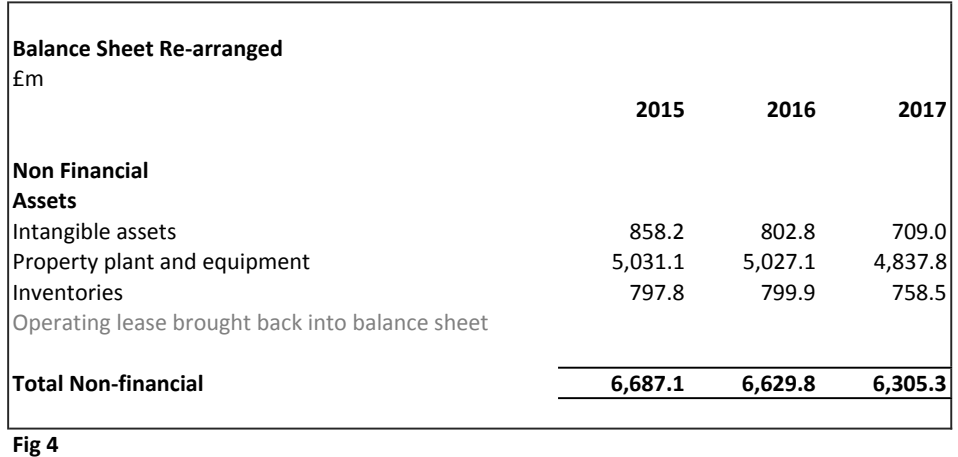

And Fig 5 shows the rearranged income statements for 2015, 2016 and 2017.

A company would have no difficulty in preparing Fig 5 by using its internal records. If we do not have access to the company's internal records, we could nonetheless arrive at the rearranged income statements by using the reported financial statements. However, deriving Fig 5 from reported financial statements requires some effort.

\begin{tabular}{|c|c|c|c|}
\hline \multicolumn{4}{|l|}{ Income Statement Re-arranged } \\
\hline Em & 2015 & 2016 & 2017 \\
\hline Revenue & $10,311.4$ & $10,555.4$ & $10,622.0$ \\
\hline Purchased goeds and service & $7,239.8$ & $7,329.9$ & $7,401.7$ \\
\hline $\begin{array}{l}\text { Adjusted items charged against purchased leases } \\
\text { less import duties, excise duties }\end{array}$ & 168.7 & 180.0 & 193.8 \\
\hline Employee costs & $1,360.7$ & $1,435.7$ & $1,491.4$ \\
\hline incl. employee costs in cost of sales 61.2 & 45.5 & 51.0 & $\begin{array}{r}61.2 \\
0.0\end{array}$ \\
\hline $\begin{array}{l}\text { Acjusted items expense charged against emp costs } \\
\text { less NICs, PAYE }\end{array}$ & 237.8 & 240.0 & $\begin{array}{r}0.0 \\
255.5\end{array}$ \\
\hline Depreciation \& amortisation & 550.1 & 576.8 & 589.5 \\
\hline Finance costs & 116.8 & 116.4 & 113.0 \\
\hline less investment income & 15.5 & 21.1 & 36.2 \\
\hline Business rates and other taxes & 184.1 & 197.1 & 193.8 \\
\hline Profit before corporte tax & 661.2 & 689.6 & 613.8 \\
\hline less corporate tax & 74.4 & 118.8 & 122.4 \\
\hline \multicolumn{4}{|l|}{ OCl gains/(losses) } \\
\hline of which gains/losses of financial assets/liabilities & 292.5 & 251.0 & -64.4 \\
\hline of which gains/losses of PPES & -28.1 & 17.1 & 19.5 \\
\hline Value added & $2,902.9$ & $3,045.5$ & $3,026.5$ \\
\hline VAT & 107.38 & 145.69 & 149.77 \\
\hline
\end{tabular}

To arrive at the rearranged income statement we first take note that the accounting identity of the income statement must satisfy the following relationship:

Revenue must equal

- Cost of purchased goods and services including customs \& excise duties +

- Employee expenses including NICs \& PAYE +

- Depreciation and amortisation charges, including charges for impairments of assets +

- Finance costs less any finance income +

- Business rates and other miscellaneous taxes + 
- Corporate tax +

- Profits after tax.

Let's consider each item of this accounting identity.

Revenue

The information for revenue is available directly from the income statement. In 2016 the revenue was $£ 10,555.4$ million. [Marks And Spencer, 2016] Note that reported revenue does not include any VAT collected at the point of sale. The company is merely acting as a collector of VAT on behalf of the government.

\section{Employee expenses}

The determination of employee expenses requires a little effort in reading both the income statement and some parts of the Notes that accompany the financial statements. So Note 10 tells us that employee costs for 2016 was $£ 1,435.7$ million. However Note 3 informs us that an additional $£ 51.0$ million employee expenses was embedded in the cost of sales. [Marks And Spencer, 2016]

However, the employee expenses of $£ 1,435.7$ million are not entirely paid to the employees; some expenses, such as NICs and PAYE, are paid as employment taxes. So, after deducting these employment taxes, the net income that employees received was $£ 1,246.7$ million.

Some employee expenses are relatively visible, provided one carefully reads the Notes To The Financial Statements. However, there are other employee expenses that are less visible. These are expenses that were incurred because during $2016 \mathrm{M} \& \mathrm{~S}$ was in the midst of some major restructuring projects. The restructuring involved the company reorganising its head office and revamping its pension schemes. M\&S also closed some UK stores and withdrew from many overseas operations. Such expenses were incurred as part of the company's long-term restructuring strategy. These expenses were not incurred as part of the company's underlying operations for the year. Current accounting standards require such expenses to be included in the income statements. However, their inclusions in the financial statements obscure our view of the company's performance in 2016.

Thankfully M\&S has thoughtfully listed these in a separate column as "adjusted items". And M\&S also included a column that shows the income statement "before adjusted items". [Marks And Spencer, 2016]

Since our interest is in the company's underlying performance, we use the data from the column before adjusted items.

\section{Depreciation and amortisation}

The income statement itself does not provide any information about depreciation and amortisation but we can derive their values, which add up to $£ 576.8$ million, from Note 3 and Note 5. [Marks And Spencer, 2016]

\section{Finance cost}

Finance cost can be derived from Note 6. [Marks And Spencer, 2016] In order that the income statement accounting identity balances, we must deduct any finance income from finance cost. Any finance gains or losses must also be netted off. So, taking these points into account, we arrive at the net finance cost of $£ 95.3$ million for 2016 . 
The company also pays, or collects on behalf of the government, various taxes, such as, national insurance contributions, employees PAYE taxes, customs duties, excise duties, taxes on business premises, corporate income tax, and value added tax. Except for corporate income tax, these taxes are not disclosed explicitly in the income statement. And value added tax (VAT), which is collected at the point of sale, of course, is not considered as the company's revenue; the company collects VAT on behalf of the government. Adding to the complication, some taxes are embedded in various expense headings in the income statement. So, for example, employment taxes are embedded within employment expenses, customs duties are embedded within purchased goods and services, and so on. The brief description of M\&S's tax contributions is revealed separately in its annual report under the heading of Total Tax Contribution. [Marks And Spencer, 2016]

\section{$\underline{\text { Profit }}$}

We can read directly off the income statement the company's profit before tax, bearing in mind that we read this profit off the column before adjusted items. Thus profit before corporate income tax, before adjustment for 2016 was $£ 689.6$ million. Profit after tax was $£ 570.8$ million. [Marks And Spencer, 2016]

\section{Cost of purchased goods and services}

Arriving at the value of purchased goods and services would not be a problem if the Accounting For Growth were done using internal records. However, deriving the answer by using the financial statements has to be by means of elimination. Like most financial statements, M\&S's financial statements do not show separately the expenses that have been incurred in purchased goods and services. So we must deduce this from other available information. Provided that we have been careful in capturing all the expenses and profit, the difference between revenue on the one hand and expenses and profit on the other hand, a difference that amounted to $£ 7,509.9$ million, would be the cost of purchased goods and services. However, out of $€ 7,509.9$ million, $£ 180.0$ was paid as customs duties and excise duties. So the amount that was actually paid to the suppliers of goods and services was $£ 7,329.9$ million.

\section{What Are Stakeholder Inputs?}

An earlier version of this paper considered only three types of resources (stakeholder inputs) that a company consumes in the course of conducting its business.

- The company needs purchased goods and services.

- The company also needs assets with which to convert purchased and services into sales.

- The company needs employees, whose skills and labour operate the assets and convert purchased goods and services into sales.

These resources are provided mostly by the company's suppliers, by its capital providers and by its employees respectively.

But a company does not operate in a vacuum. The company relies heavily on the infrastructures and institutions and other public goods that exist in the market. Rightly, these are also resources that contribute to the generation of the company's revenue. Negative externalities, such as pollution, impose costs on society and, in that sense a polluting company also is consuming the clean environment. In this paper we will estimate and incorporate the consumption by the company of such public goods. 
We shall denote the resources provided by goods and services as $\mathbf{M}$, and denote the resources provided by skills and labour as $\mathbf{L}$, and resources provided by capital as $\mathbf{K}$ and public goods and negative externalities consumed by the company as $\mathbf{G}$.

Recall that the re-arranged balance sheet shows how the total asset equals the net funding of the company. So we could also view $\mathbf{K}$ as the resources that assets contribute to the generation of revenue.

Without the input of $\mathbf{M}$, i.e. purchased goods and services, $M \& S$ would have had nothing to sell and would not have been able to generate its revenue of $£ 10,555.4$ million in 2016. So what count as purchased goods and services? Purchased goods and services in the case of M\&S clearly would include apparels and clothing accessories as well as agricultural produce and prepared food. However, in addition to the merchandises that we would normally associate with M\&S stores, the company also purchases many goods and services that it does not sell. These are goods and services, such as leased facilities, office supplies and auditing services that the company consumes in the course of conducting of its business.

It should be noted that in principle, $\mathbf{M}, \mathbf{L}, \mathbf{K}$, and $\mathbf{G}$ are measures of the quantities of three different types of input that, in combination, generated the revenue of $£ 10,555.4$ million. However, usually each type of input is made up of many disparate items. And because they are disparate, there is no practical way to add them. So for example, assets might comprise buildings, some large and some small, computers, lightings and so on. What is the aggregate number for, say, 10 buildings plus 1,000 computers? It is not practical to measure such quantities directly. So in Accounting For Growth we use proxies to represent the quantities of $\mathbf{M}, \mathbf{L}, \mathbf{K}$ and $\mathbf{G}$. This point will become clear as this discussion progresses.

In the course of a year, $M \& S$ purchases myriad goods and services. Even if the financial statements provide detailed information, which they don't, it would be impractical to add the number of different types of dresses to the number of different grades of socks and the number of tomatoes and so on and say that the resulting number is the quantity M. Since we know that M\&S purchased $£ 7,329.9$ million of goods and services in 2016, we take that value as a proxy to represent the quantity of all these goods and services collectively. And, by the way, the amount in 2015 was $£ 7,239.8$ million. Later we will discuss how Accounting For Growth uses indices to represent $\mathbf{M}, \mathbf{L}, \mathbf{K}$ and $\mathbf{G}$ but here is a quick preview of $\mathbf{M}$ as an index. If we set $\mathbf{M}$ in 2015 as the baseline of 1.0 (or if you like, if we say that $£ 7,239.8$ million of purchased goods and services represents one unit of M), then in 2016 M\&S would have purchased $1.0125 \mathrm{M}$ of goods and services.

Note: Numbers shown may not add up exactly because of rounding.

The assets that M\&S deploys in its business may involve real estate properties that house its stores and offices, equipment such as computers, fittings and fixtures that turn a building into a store, and inventories that eventually get converted into sales. (Any buildings that M\&S leases, i.e. buildings that M\&S does not own, count as purchased services, although this probably would change starting 2019 because of changes in accounting rules).

A short explanation about, $\mathbf{K}$, the resource provided by capital, is in order here. Recall that in the re-arranged balance sheet, we noted that the sum of all non-financial assets was equal to the net balance of the sum of all financial assets and liabilities. In Accounting For Growth, capital, $\mathbf{K}$, is not the sum of total financial liability plus equity less financial assets. So it is not the sum of non-financial assets. In Accounting For 
Growth, $\mathbf{K}$ describes how much a company's assets contribute, in conjunction with employees' effort and suppliers' goods and services, to the generation of the company's revenue. Perhaps $\mathbf{K}$ is best explained using an example to illustrate the difference in assets' contribution between a long-life asset and a short-life asset, both having the same market value, say, of $£ 1,000$. Let's assume that the long-life asset will provide service to the company for 100 years whereas the short-life asset will provide service for only 10 years.

Clearly the company would expect to receive more service per year from the short-life asset than from the long-life asset. We have to assume that a rational company would not want to employ more assets than necessary to carry on its business. There are two costs associated with the owning and use of assets. There are firstly the depreciation charges that spread the assets' acquisition costs over the lives of the assets. And then there are the opportunity costs of tying up funds in the acquisition of the assets, which otherwise could earn a return in other investments. If the company were to lease these assets, the depreciation charges plus the opportunity costs would be replaced by an annual payment for the rental of these assets. In Accounting For Growth we use the depreciation plus opportunity cost (or the equivalent rental cost) as a proxy for the quantity of services the company receives from its assets.

Unfortunately, financial statements generally do not provide enough information for us to determine the value and life span of a company's specific assets, although this information should be readily available if we have access to the company's internal records. Nonetheless, we can estimate what might have been the equivalent annual payment for rental if assets were all leased.

We have earlier established that the total of all non-financial assets in 2016 was $£ 6,629.8$ million and that depreciation was $£ 576.8$ million. We need the lifespans of each asset in order that we can calculate the aggregate capital contribution $\mathbf{K}$. Such information of course is readily available in the company's internal records. However, if we have only the company's published financial statements to go by, we are forced to make an estimate that is probably not totally accurate. We estimate the average lifespan of the company's total non-financial assets as if the company had only one large nonfinancial asset of $£ 6,629.8$ million with a lifespan of 11.5 years.

$\frac{£ 6,629.8 \text { million }}{£ 576.8 \text { million }}=11.5$ years

$M \& S$ has both operating leases and finance leases. From Note 21 , we note that the effective interest rate for finance leases was $4.1 \%$, which we take as also the effective interest rate if all assets were leased. So the depreciation and opportunity costs of owning $£ 6,629.8$ million of assets is given by the equation

$\frac{£ 6,629.8 \times 4.1 \% \times(1+4.1 \%)^{11.5}}{(1+4.1 \%)^{11.5}-1}$ million

$=£ 734.9$ million

In short, M\&S should expect to receive $£ 734.9$ million per year of services from all its assets. That is the 2016 value of $\mathbf{K}$. (The value of $\mathbf{K}$ in 2015 was $£ 709.5$ million).

The third resource, $\mathbf{L}$, that a company requires is the skills and labour of its employees. According to Note 10 to the financial statements, if the number of hours worked was converted on the basis of a normal working week, the equivalent average number of full- 
time employees in 2016 was 58,895 (it was 59,096 in 2015). Perhaps you might question why the equivalent number of employees should be used to represent $\mathbf{L}$. After all, firstly, doesn't the value add of an employee depend on her skills level? And secondly, since $\mathbf{M}, \mathbf{L}, \mathbf{K}$ and $\mathbf{G}$ are of different dimensions, how are we going to add them up to arrive at an aggregate of the resources that was deployed by M\&S to generate $£ 10,555.4$ million of revenue?

Let's first address the second question. Indeed, the proxies we use for $\mathbf{M}, \mathbf{L}, \mathbf{K}$ and $\mathbf{G}$ measure very different things. $\mathbf{M}$ measures in $€$ the value of goods and services purchased by the company. And $\mathbf{K}$ is also measured in $€$ but it measures the depreciation and opportunity costs. But $\mathbf{L}$ isn't measured in $€$ at all. (More about $\mathbf{G}$ later). Fortunately, we are measuring growths and we are interested to know how the growths of $\mathbf{M}, \mathbf{L}, \mathbf{K}$ and $\mathbf{G}$ contributed to the growth in revenue. That being the case, we could set an index of 1.0 for each of $\mathbf{M}, \mathbf{L}, \mathbf{K}$ and $\mathbf{G}$ in 2015. Or if you like, we say that 59,096 employees equal one unit of $\mathbf{L}$. So, for example, if we denote the index for $\mathbf{L}$ in 2016 as $\mathbf{L}_{2016}$ and we denote as $\mathbf{L}_{2015}=1.0 \mathbf{L}$, then $\boldsymbol{L}_{2016}=\frac{58,894}{59,096}=0.9966 \boldsymbol{L}$

Regarding the first objection, indeed not all employees contribute to the same degree to the company's business. And the skills level of employees may not be the same from one year to the next, even though in most cases any increase in skills level may not be substantial in the course of one year. But how does one measure skills level? Is it equated to the number of years of relevant working experience? Or should it be equated to education level? The only objective number to represent $\mathbf{L}$ is the number of employees. This does not mean that skills level is not considered in Accounting For Growth. It simply means that we will capture any increase in skill level as part of part of the ability to handle tasks that hitherto had not been undertaken, or had not been undertaken to the same extent, by the company. That ability expresses itself as the possibility for the company to switch from an operation requiring more resources, as would be the case for a labour intensive operation, to an operation that can produce the same output but requiring less resources.

We then do the same calculations for $\mathbf{K}$ and $\mathbf{M}$.

At first glance the measurement of $\mathbf{G}$ may seem problematic. How do we measure how much of the road network, or how much of the port, or airwaves, the company consumes in a year? And how do we put a value to how much a company pollutes the air, or the waterways, or how much the company contributes to congestions on the roads or at the ports? So it is probably quite impossible, based on current state of economics theories, to put a value for $\mathbf{G}$ for $M \& S$ and compare that with the value of $\mathbf{G}$ for, say, Monsanto. This deficiency in the current state of economics theory afflicts all corporate performance metrics. A company that pollutes, or produces goods that damage the health of its consumers, and gets away with it would show a higher returns on equity (ROE) than if it were required to bear (i.e. internalise) the costs of its negative externalities. Accounting For Growth, likewise, suffers from this deficiency when used to compare performance between companies. However, notwithstanding that, it is quite possible to compare M\&S's G in 2016 with its $\mathbf{G}$ for 2015, using our idea of indices. But first, we have to choose an appropriate proxy to measure the value of $\mathbf{G}$.

We can safely assume that the company consumes some amount of public goods and creates some amount of externalities at each stage its operations, from say, ordering and receiving goods, through warehousing, advertising and promotion, to eventually sales of its merchandises at the stores. And we can assume that the amount of public goods and 
externalities at each stage is proportional to the scale of operations. Now, there is this concept called value-added. [Morley, 1979] It is the aggregate value that a company generates when engaging in its many activities throughout many stages of its operations. So, the amount of public goods that a company consumes and the amount of externalities that it creates is proportional to the company's value-added. Notice too that the company's value-added does not include its suppliers' value-added. That is because the public goods consumed and externalities created by the suppliers are not part of the value of $\mathbf{G}$ of the company. So, a company's value-added is a good proxy for measuring the public goods that the company consumes.

But how do we know what the value-added of a company is? If we consider the accounting identity of the income statement, we would come to this conclusion, that the company's value-added is the sum of:

- Employee expenses including NICs \& PAYE +

- Depreciation and amortisation charges, including charges for impairments of assets +

- Finance costs less any finance income +

- Business rates and other taxes +

- Corporate tax +

- Profits after tax.

And that is equal to:

- Revenue

- less cost of purchased goods and services including customs \& excise duties

Fig 5 shows that the value-added for 2016 was $£ 3,045.5$ million and for 2015 it was $£ 2,902.9$ million.

Recall that in 2016, M\&S also generated $£ 145.7$ million value added tax (VAT). But that value was not part of M\&S's reported revenue because that amount accrued to the government. Nonetheless, the $£ 145.7$ million of VAT was a direct result of the company's sales and should be counted as contributing to the gross value-added in 2016.

So taking all these points into consideration, we say that the index for $\mathbf{G}$ in 2016 is 1.0491 .

Since $\mathbf{M}, \mathbf{L}, \mathbf{K}$ and $\mathbf{G}$ are transformed into indices, there will be no problem in adding or multiplying the three inputs.

In summary, the indices for 2016 are

$\mathbf{M}=1.0125$

$\mathbf{L}=0.9966$

$\mathbf{K}=1.0358$

$\mathbf{G}=1.0491$

\section{The Input Structure Equations}

Let's start with an analogy to explain the concept of stakeholders input structure.

A company needs funds to finance its business operations. And the company's funding is often a combination of debts and equity. Not all debts are the same. Some have longer maturity, some very short, some are secured against the company's assets, and some are unsecured. Similarly not all equity is the same. The composition of the company's funding is called its capital structure. 
Notice that so far, nothing has been said in this paper about capital structure. Equity and debt have been lumped together as a single type of inputs, treating shareholders and creditors similarly as providers of capital. Of course, there are important differences between equity and debts. The ratio of debt to equity is an important corporate finance decision. It has a significant impact on a company's profits and it affects the company's liquidity risks. However, there already exists ample number of corporate finance tools to find an optimum debt to equity ratio. So these corporate finance tools can be put to work to choose the ratio between equity and debt once the optimum size of capital has been determined. Later in the paper it will become clear that Accounting For Growth is an appropriate tool to determine the optimum size of capital.

Well, just as the concept of capital structure describes the composition of a company's capital, the concept of input structure describes the composition of the company's inputs, including, but not limited to, its capital. Recall that a company requires four categories of resources, $\mathbf{M}, \mathbf{L}, \mathbf{K}$, and $\mathbf{G}$, which we will name as inputs to production. For our purposes, four broad categories of entities provide the inputs that the company requires to carry on its business. Investors and lenders provide the funding. Employees provide the skills and labour. Suppliers provide the goods and services. And society provides the public goods and bears the consequences of the company's externalities.

When revenue grows, intuitively we expect that these inputs to production must have also grown. How much must each of the inputs grow to support the growth in revenue? It depends. If in the meantime the conversion of these inputs to revenue has become more efficient, the inputs may not have to grow as much. If the inputs are interchangeable, and some inputs are more efficient than others, then through a judicious combination of inputs, the company may be able to grow faster but requiring less resources. And generally inputs may not have to grow to the same extent for revenue to grow because of economy of scale, but sometimes growth may be had with diminishing returns

All these variable conditional scenarios make the answer to the question seem almost insurmountable. But it is not insurmountable if we break up the analysis into separate steps. So as a first approximation we simplify by imposing some restrictions to our analysis. We then relax some of the restrictions in subsequent steps.

As a first step, we impose the restrictions that there is no economy of scale; we assume proportionality. In other words we assume that the inputs must increase in proportion to the growth in revenue. However, we allow for some degree of inter-changeability between the inputs. In other words, a $1 \%$ rise in revenue would have been accompanied by a $1 \%$ rise in the input structure of $\mathbf{M}, \mathbf{L}, \mathbf{K}$ and $\mathbf{G}$ as an aggregate but the composition of the input structure is allowed to vary.

The solution, given proportionality, is simple if each of the inputs rises by the same percentage. If revenue grows by $1 \%, \mathbf{M}, \mathbf{L}, \mathbf{K}$ and $\mathbf{G}$ each would have to increase also by $1 \%$. However, what if the inputs change by different amounts? This might happen perhaps because the inputs are inter-changeable. For example a company might choose to acquire and own a building that it previously leased. That would reduce $\mathbf{M}$ and increase $\mathbf{K}$, since a leased building is a purchased service whereas a building owned by the company is an asset. Or the company might outsource its logistics to a third-party, in which case $\mathbf{M}$ would increase, and $\mathbf{L}$ and possibly $\mathbf{K}$ might decrease.

How can we handle the mathematics given proportionality and inter-changeability? Before we get to the mathematics, I have to introduce four more variables, $\mathbf{m}, \mathbf{l}, \mathbf{k}$ and $\mathbf{g}$. In Accounting For Growth we take the view that the revenue, plus its corresponding 
VAT, is allocated to (or the revenue plus VAT accrues to, if you like) the providers of the four inputs to production. Suppliers get paid for their goods and services. We denote suppliers' share of the revenue as $\mathbf{m}$. Employees are paid for their skills and labour. We denote employees' share of the revenue as $\mathbf{l}$. Society is recompensed for its public goods and externalities. (Note: VAT accrues entirely to society). We denote society's share of revenue plus VAT as $\mathbf{g}$. The remainder of the revenue is the lenders' and investors' share of the revenue. We denote that as $\mathbf{k}$. In other words, $\mathbf{m}, \mathbf{l}, \mathbf{k}$ and $\mathbf{g}$ are returns on stakeholders' input contributions.

Fig 6 tabulates the shares of $\mathbf{m}, \mathbf{l}, \mathbf{k}$ and $\mathbf{g}$ to be used for M\&S's Accounting For Growth in 2016. Obviously the sum of all the shares of revenue equals $100 \%$ of the revenue, i.e. $\mathbf{m}+\mathbf{l}+\mathbf{k}+\mathbf{g}=1.00$

It should be noted that the shares of revenue $\mathbf{m}, \mathbf{l}, \mathbf{k}$ and $\mathbf{g}$ are related to but are not the same things as the inputs $\mathbf{M}, \mathbf{L}, \mathbf{K}$ and $\mathbf{G}$. For example, $\mathbf{K}=£ 734.9$ million. That is the proxy measure that represents the quantity of capital used to generate $£ 10,555.4$ million of revenue. However, $\mathbf{k}=£ 1,309.6$ million. That is the portion of the revenue that accrues to the providers of the capital.

An easy way to visualise the difference is to think that $\mathbf{K}$ and $\mathbf{k}$ flow in opposite directions.

Fig 7 is a summary of the index numbers for $\mathbf{M}, \mathbf{L}, \mathbf{K}$ and $\mathbf{G}$ for M\&S in 2016.
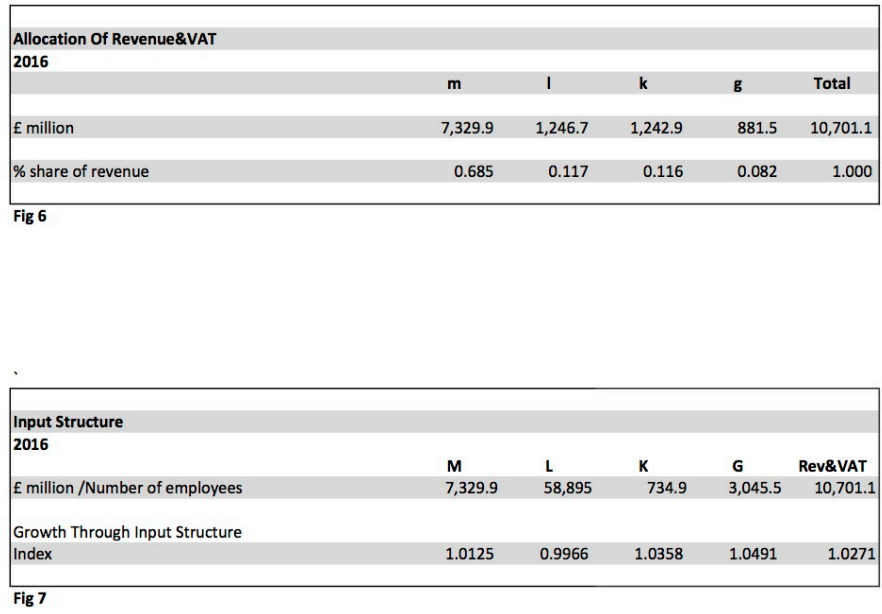

Now we are ready to search for an equation for proportionality that can take into account inter-changeability. How does revenue plus VAT vary when the inputs change? In other words, how does revenue plus VAT vary when the input structure changes?

It depends on whether the company has the ability to maximize economic returns by switching between inputs.

First, let's examine the implications if there were absolutely no room for inter-changing between the four inputs of production. How responsive would revenue have been to changes to the input structure? Revenue would have changed in proportion to the smallest increase (and that means also in proportion to the largest decrease) of the four inputs. In 2016, the number of employees, $\mathbf{L}$, dropped by $-0.34 \%$. If M\&S made absolutely no attempt to optimise its input structure, then given our proportionality 
assumption, revenue should have fallen by a corresponding $-0.34 \%$ (which of course was not the case).

Perhaps a hypothetic case (not a realistic one) will make this point clear. Let's assume that half of all stores were leased. Now suppose that for some reasons all leases have to be terminated immediately and there is no desire, or no opportunity to replace these leases with new leases and there is no way that $M \& S$ can acquire and own more stores itself. So there is no inter-changeability between purchased services, $\mathbf{M}$, and owned assets, $\mathbf{K}$. And suppose that there is no way to transfer staffs and goods to the remaining stores, and that even if such transfers were possible, they would not add to the remaining stores' ability to generate more sale. So there is no inter-changeability between the assets, $\mathbf{K}$, and the number of employees, $\mathbf{L}$ and purchased goods, $\mathbf{M}$.

In this hypothetic case, revenue would depend entirely on the ability (i.e. efficiency) of the remaining stores to generate sale.

So if the company is unable, for whatever reason, to switch between inputs, the revenue growth is limited by the smallest growth among the inputs of production. Such a situation can be characterized by an equation

$\mathbf{R}=\mathbf{a} \times \min (\mathbf{M}, \mathbf{L}, \mathbf{K}, \mathbf{G})$. This is called the Leontief equation. [Csontos, Ray 1992]

Take the case of M\&S's revenue growth in 2016. If we assume direct proportionality, and ignore for the time being the variable a (we will determine the value of a later), $M \& S$ 's revenue growth would have been determined by the negative growth of employment, i.e.

$\mathbf{R}_{2016}=\min (1.0125,0.9966,1.0358,1.0491) \mathbf{R}=0.9966 \mathbf{R}$

The Leontief equation represents an absolutely rigid system. However much $\mathbf{M}$ and $\mathbf{K}$ or $\mathbf{G}$ might increase, they would have no effect on $\mathbf{R}$ so long as the limiting inputs is $\mathbf{L}=$ 0.9966 .

Of course, in reality there is always some room to replace some parts of an input to production with another. So a more commonly used equation, one that is favoured by economists, is the Cobb Douglas equation, which we can re-write as

$\mathbf{R}=\mathbf{a} \times \mathbf{M}^{\mathbf{m}} \times \mathbf{L}^{\mathbf{l}} \times \mathbf{K}^{\mathbf{k}} \times \mathbf{G}^{\mathbf{g}}$. [Douglas, 1976]

The Cobb Douglas equation is in fact unsolvable using indices (except when all inputs of production, or when the returns to all stakeholders change by the same ratios). So the equation often is approximated by assuming that the returns to stakeholders from one period to the next are the averages of the returns of the two periods.

Notice that if we ignore the variable, $\mathbf{a}$, for the time being, $\mathbf{R}$ increases in direct proportion to changes in the input structure. In other words, if $\mathbf{M}, \mathbf{L}, \mathbf{K}$ and $\mathbf{G}$ increase by, say, $10 \%$, i.e. if $\mathbf{M}=1.10, \mathbf{L}=1.10, \mathbf{K}=1.10$ and $\mathbf{G}=1.10$, then

$\mathbf{R}=\mathbf{a} \times\left(1.10^{0.685} \times 1.10^{0.117} \times 1.10^{0.116} \times 1.10^{0.082}\right)=1.10 \times \mathbf{a}$

Furthermore, notice that this equation can handle proportionality even when the inputs to production do not all change by the same degree. So in the case of M\&S in 2016,

$\mathbf{R}=\mathbf{a} \times\left(1.0125^{0.685} \times 0.9966^{0.117} \times 1.0358^{0.116} \times 1.0491^{0.082}\right)=1.0162 \mathbf{a}$ 
In other words M\&S's revenue growth in 2016, assuming proportionality and ignoring the variable a, would have been

$\mathbf{R}=1.0162$, i.e. $1.62 \%$ growth

Since the actual realized growth was $2.71 \%$,

$\mathbf{a}=\frac{1.0271}{1.0162}=1.0107$

People familiar with productivity measurements would recognise that the variable, a, is the company's multifactor productivity for 2016, relative to 2015. For simplicity, we will dispense with showing the variable, $\mathbf{a}$, for the time being, bearing in mind that $\mathbf{R}$ in fact should be $(\mathbf{R} \div \mathbf{a})$.

In recent years, the Constant Elasticity Of Substitution (CES) equation, which was first derived by Arrow, Chenery, Minhas, and Solow, has been gaining favour. It is a generalized equation of which the Leontief and Cobb Douglas versions can be viewed as special cases. [Arrow, Chenery, Minhas, Solow, 1961] When applied to an individual firm, we can rewrite the equation as an input structure equation

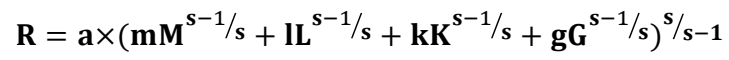

When $\mathbf{s}=0$, revenue $\mathbf{R}$ takes the value of the Leontief equation. When $\mathbf{s}=1.0, \mathbf{R}$ assumes the value of the Cobb Douglas equation.

Let's check that indeed the CES equation meets the condition of proportionality. In other words, if we increase each of the inputs, $\mathbf{M}, \mathbf{L}, \mathbf{K}$ and $\mathbf{G}$ by, say, $1 \%$, we should expect revenue, $\mathbf{R}$ to also increase by $1 \%$, no matter what the value of $\mathbf{s}$ might be.

In Fig 8 we construct a hypothetical table to demonstrate the properties of the proportionality of this CES equation of input structure. The table has one row that repeats the shares of revenue plus VAT, i.e., $\mathbf{m}, \mathbf{l}, \mathbf{k}$ and $\mathbf{g}$, that accrue to suppliers, employees, capital providers and society. The table also has two rows titled Uniform Proportionality, which show hypothetical indices for the inputs $\mathbf{M}, \mathbf{L}, \mathbf{K}$ and $\mathbf{G}$ all having the value of 1.010. That means each of the inputs has increased by $1 \%$. The column $\mathbf{R}$ shows the result of applying the input structure equation, which in the case when $\mathbf{s}$ $=2.00$, the equation takes the values

$\mathbf{R}=\left(0.685 \times 1.011^{\frac{2-1}{2}}+0.117 \times 1.010^{\frac{2-1}{2}}+0.116 \times 1.010^{\frac{2-1}{2}}+0.082^{\frac{2-1}{2}}\right)^{2 /(2-1)}=1.010$

So the input structure equation satisfies the proportionality condition when $\mathbf{s}=2.00$.

The proportionality condition also implies that when all the inputs increase by the same percentage, say, $1 \%$, revenue $\mathbf{R}$ is expected to increase by $1 \%$, even when the value of $\mathbf{s}$ is different. If we look further down the table to the next row on Uniform Proportionality, we find that $\mathbf{R}$ indeed remains as 1.010 even though $\mathbf{s}$ is now 0.005 .

$\mathbf{R}=\left(0.685 \times 1.010^{\frac{0.005-1}{0.005}}+0.117 \times 1.010^{\frac{0.005-1}{0.005}}+0.116 \times 1.010^{\frac{0.005-1}{0.005}}+0.082 \times 1.010^{\frac{0.005-1}{0.005}}\right)^{0.005 /(0.005-1)}$ 
Notice that Fig 8 also has two rows titled Uneven Proportionality. In these rows, whereas, $\mathbf{M}$ increases by $1 \% \mathbf{m} \mathbf{L}, \mathbf{K}$ and $\mathbf{G}$ are kept constant (i.e. at $0 \%$ increase). Intuitively, we expect that the total overall growth would be greater than $0 \%$ but less than $1 \%$, which indeed are the case for both rows. However, the total overall growth is different for the two rows. Why these two rows produce different results would become clear later as we discuss the shape of the curves in Fig 9 and fig 10.

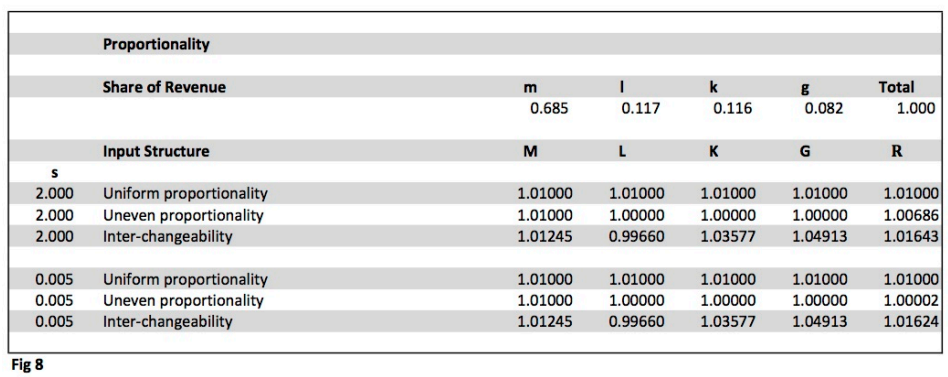

We now apply the CES input structure equation to the actual M\&S 2016 results that were tabulated in Fig 6 and Fig 7.

$\mathbf{R}=\left(0.685 \times 1.0110^{s-1 / s}+0.117 \times 0.9966^{s-1 / s}+0.116 \times 1.0358^{s-1 / s}+0.082 \times 1.0524^{s-1 / s}\right)^{s / s-1}$

Now if we plot the revenue plus VAT, $\mathbf{R}$, for different values of $\mathbf{s}$, we obtain the chart shown in Fig 9. Notice that the value of $\mathbf{R}$ does not increase indefinitely with increasing values of $\mathbf{s}$. That is, $\mathbf{R}$ has a limiting value. In this particular case, the limiting value for M\&S 2016 is 1.0163 . This chart shows only the part of the curve for a partial range of values for $\mathbf{s}$ from 0.05 to 0.5 . By charting only a partial range, the non-linear relationship, between $\mathbf{R}$ and $\mathbf{s}$, is easily visible.

It's important here to bear in mind that the value of a that is derived using the Leontief equation is different from the value of a using the Cobb Douglas equation and those are different from the value of a using the CES equation when $\mathbf{s}$ is not equal to zero or to one.

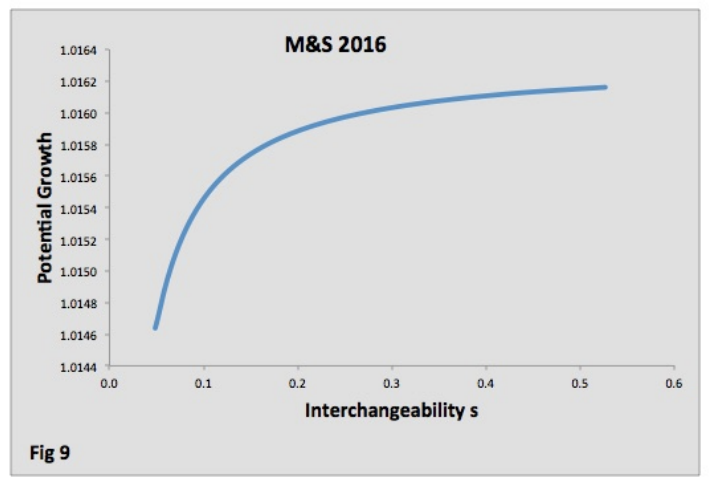

From now on, we stay with the CES equation. Fig 10 shows a wider range of $\mathbf{s}$, from 0.0 to 3.0. Notice that when $\mathbf{s}=1.0, \mathbf{R}=1.0162$, as predicted by the Cobb Douglas equation.

It is easy to misread the implication of this chart. At first glance, it looks like the curve traces a rotated "L" shape whereas in actual fact, it is really an " $\mathrm{S}$ " curve. If we had plotted the chart with very small increments for values of $\mathbf{s}$, e.g. in increments of 
0.00002 instead of increments of 0.5 , we would have discovered that $\mathbf{R}$ in relation to $\mathbf{S}$ traced an "S" curve, except that the lower tail of this S-curve would have been very short. We would have also found that the lower bound of the curve was 0.9966 when $\mathbf{s}=0$, as predicted by the Leontief equation. And when $\mathbf{s}=1.0$, we find that $\mathbf{R}=1.0162$, as predicted by the Cobb Douglas equation.

The CES input structure equation predicts that the upper bound of the S-curve reaches a maximum of 1.0163 with increasing value of $\mathbf{s}$.

Notice that in terms of determining the maximum expected growth (assuming proportionality), given a specific input structure, the Cobb Douglas result usually is a good approximation. However, the true advantage of the CES formula is that, when comparing different input structures, the inter-changeability index, $\mathbf{s}$, is a far more sensitive measuring tool than the multifactor productivity index, $\mathbf{a}$.

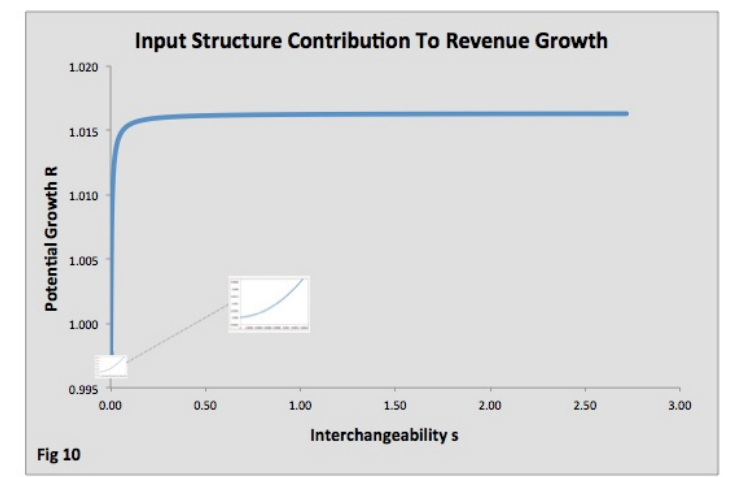

So according to the CES input structure equation, revenue plus VAT in 2016 should have grown by no more than $1.63 \%$ but we know that in fact M\&S's revenue plus VAT grew by $2.71 \%$.

The fact that the maximum expected growth is lower than the actual growth tells us that the proportionality solution to the CES input structure equation does not provide a full explanation for the $2.71 \%$ (or $2.37 \%$ of revenue alone) growth of 2016 .

That the revenue plus VAT grew by more than $1.63 \%$ means that M\&S had outperformed expectations. The company could have successfully capitalised on economy of scale. Or perhaps its merchandisers acquired new skills in purchasing. Or sales staff excelled in customer service. There are countless "x-factors" that could have contributed to the superior performance. This catchall " $\mathrm{x}$-factors" is represented by the multi-factor productivity, a.

We could continue this line of analysis and discover how economy of scale (or conversely diminishing returns) might explain part of the difference, but in the interest of staying focused we will leave that for another occasion. For now, we will take the standard approach. We shall say that the difference represents the contributions from " $x$-factors", which collectively, are called the multi-factor productivity. So all things being equal, if we set aside the contribution from economy of scale or multi-factor productivity, the changes in input would have increased revenue plus VAT by 1.63\%. In a future discussion of Accounting For Growth, we shall discover that economy of scale contributed $0.84 \%$ to $M \& S^{\prime}$ s 2016 growth in revenue.

Before we proceed to consider 2017, we shall wrap up our discussion of 2016 with some simple illustrations of some possible applications of Accounting For Growth. We shall 
consider how a corporation might use Accounting For Growth to assess how a change in its input structure might affect the aggregate returns to all stakeholders. We follow that with a brief discussion about how a corporation might use Accounting For Growth to decide whether it should outsource or keep a particular operation in-house.

Let's go back to study the chart in Fig 10. This is what the CES growth curve says: For a given set of input structure, revenue growth (and the corresponding VAT growth) is higher when the value of inter-changeability, $\mathbf{s}$, is larger. Conversely, for a given revenue growth, if the inter-changeability, $s$, is high, the company is generating its growth with less resources. Recall that a company's revenue and VAT accrue to all its stakeholders and that the inputs are the resource contributions of all stakeholders. So if the same revenue plus VAT could be had for less inputs, that translates to higher returns to all stakeholders.

Bear this in mind, for we will use this idea to answer whether a change in input structure represents an improvement in resource utilisation.

\section{Scenarios $1 \& 2$}

Let's start with two simple scenarios. Food spoilage is a major cost for grocery retailers. We assume that M\&S might save $£ 10$ million if it could cut spoilage by, say, $0.3 \%$. For this simple example, we simply say that cutting wastage by $£ 10$ million amounts to spending $£ 10$ million less on purchases. We assume that there is no change to either the assets or employment. Intuitively we know that cutting wastage must be an improvement, no matter from which point of view we consider this, whether it is from the point of view of society, or shareholders, or any other stakeholder.

Recall that the chart of Fig 10 shows how the CES expected growth depends on the company's input inter-changeability, $\mathbf{s}$. A higher value of $\mathbf{s}$ implies higher CES expected growth for a given input structure. Conversely, for a given revenue growth, a higher interchangeability, $\mathbf{s}$, implies that the company is able to achieve the same CES expected growth but with lower aggregate of inputs, i.e. with less resources. And therefore higher interchangeability means higher returns to all stakeholders.

The scenario we have posed ourselves is essentially a comparison between two sets of input structure. One of the sets is the actual input structure as defined by Fig 7 . The other set of input structure is a variation with less input of purchased goods and services.

Let's remind ourselve what we desire to find out. We want to know which set of input structure has a larger value for interchangeability, $\mathbf{s}$, for the same expected CES proportionality growth, $\mathbf{R}$, of 1.0163 . Here we encounter a dilemma. When the actual realised growth is greater than the maximum expexted growth based on the CES input structure equation, the value of the interchangebility, s, becomes very large. In that case, we might end up comparing two very large numbers. We can still evaluate mathematically the two sets of input structure to see which gives a higher value for $\mathbf{s}$ for the same growth of 1.0163. But for our purpose it is easier to see the difference if we plot the CES growth curves for the two sets of input structure.

And since we are comparing the values of $\mathbf{s}$ for a given growth, R, of 1.0163, in Fig 11 we plot the CES curves with the growth, $\mathbf{R}$ as the horizontal axis and interchangeability, $\mathbf{s}$, as the vertical axis. We name the curve for reduced wastage as the What If curve. 
Notice that for the same growth, the What If curve is above (i.e. to the left of) the curve for the actual 2016 input structure. That is to say, the What If curve has a larger value for $\mathbf{s}$ than the curve for the actual 2016 set of input structure.

We conclude that, as we expected, cutting wastage by $£ 10$ million represents an improvement.
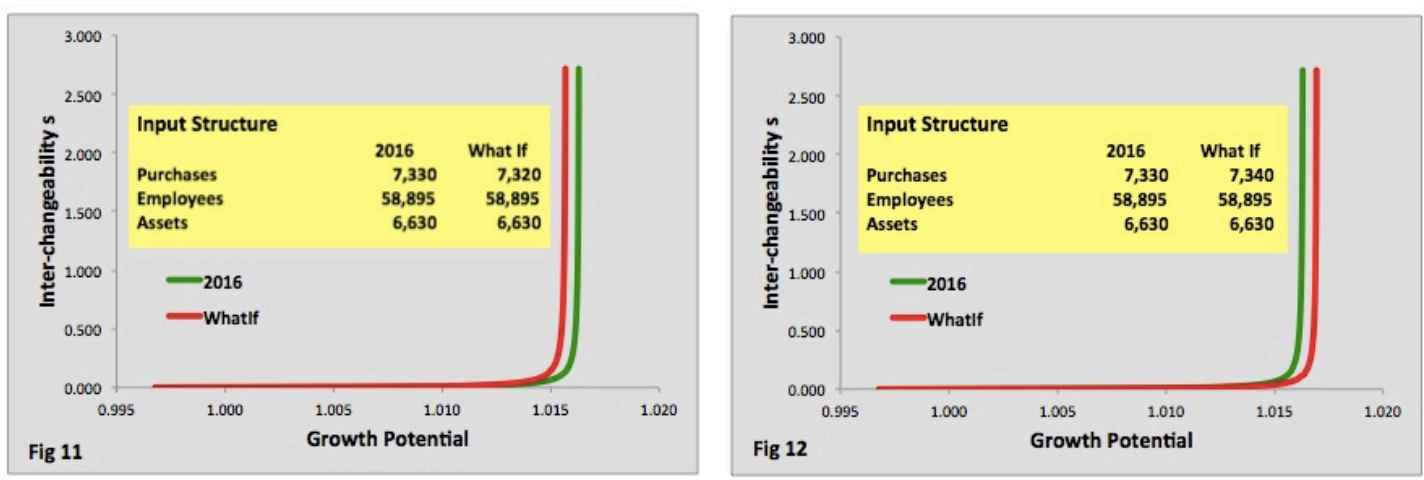

Next, we consider the converse situation. We imagine that wastage were $£ 10$ million higher. In other words, purchased goods and services were $£ 7,340$ million instead pf $£ 7,330$ million. Assets and employment remain the same.

In Fig 12 again we plot the two curves, one for the actual 2016 input structure the other with $£ 10$ million higher for purchased goods and services. As expected, the What If curve is lower than (i.e. to the right of) the actual 2016 curve, demonstrating that Accounting For Growth is consistent with our expectations.

\section{Scenarios 3 \& 4}

Next we add some complexity to the scenarios. We imagine that the company is assessing whether it should undertake a particular task in-house or that it should continue to outsource that task. We assume that whether the task is undertaken inhouse or outsourced, that decision has no material effect on the company's revenue. In other words, revenue plus VAT growth, $\mathbf{R}$, remains as 1.0163.

It turns out that the answer can be different depending on whether the company would make its decision to maximise profit or it would make its decision to minimise its consumption of resources, which would maximise returns to all stakeholders. That is, whether the decision would be based on its impact on P\&L or based on its impact on input interchangeability, $\mathbf{s}$. It depends on whether the company maximises shareholders returns or it maximises aggregate stakeholder returns.

Let's assume a particular task is currently outsourced at the cost of $£ 20$ million per year. What if the company chooses not to outsource the task, i.e. what if the company wishes to take the task in-house? We examine two different scenarios to illustrate how the company might evaluate each scenario based on Acounting For Growth.

In this (\#3) scenario, we assume that the company can perform the task by employing 355 more workers at the cost of $£ 7.5$ million. Revenue will not be affected. In addition, the task will require $£ 5$ million investment in equipment. No other significant changes are required to take the task in-house. Profit is expected to increase by about $£ 12$ million.. 
In Fig 13 we plot the CES curves, keeping the growth, $\mathbf{R}$, as the horizontal axis and interchangeability, $\mathbf{s}$, as the vertical axis. The What If input structure and the actual 2016 input structure are shown as an inset within the chart.

Notice that the What If curve of Fig 13 lies to the left of the actual 2016 curve, indicating that the company should take the task in-house.

Now we consider Scenario \#4, in which the company wishes to take back a $£ 20$ million outsourced task, and perform it in-house. But that would require employing an additional 700 employees at the cost of $£ 15$ million and new equipment costing $£ 15$ million. Fig 14 plots the resulting What If curve and the actual 2016 curve. Notice that in this scenario the What If curve of Fig 14 lies to the right of the actual 2016 curve, indicating that the company should not take the task in-house. This, despite a potential $£ 3$ million increase in profit.
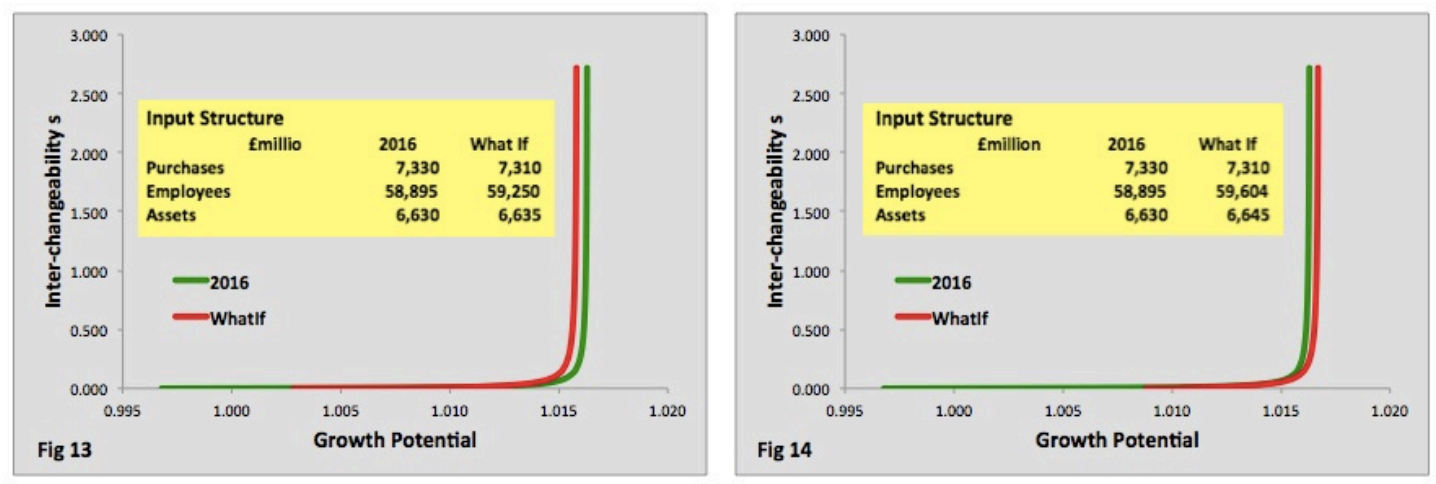

\section{Optimising Wage Distribution}

Wage distribution is an emotive issue these days, especially after the Occupy Wall Street protests. The general consensus these days seems to be that top executives should be paid less and the rest of the company should be paid more.

But what does Accounting For Growth have to say about wage distribution?

The question we want answered is this: Was the 2016 wage distribution optimum? Recall that earlier we established that a company that is operating at a higher interchangeability is capable of generating more revenue (i.e. has higher growth potential) with less inputs. (Later we will create a hypothetical case where the only resource variables in the input structure are the ratios of low wage to high wage workers)

If we were using M\&S's internal data, we could answer that question for any cohort of workers. For example we could ask: What if cashiers were paid higher wages?

Unfortunately financial statements do not provide much information about who gets paid how much. So to demonstrate how Accounting For Growth approaches the matter of wages, we would have to devise a hypothetical case, a very simplistic (and quite unrealistic) one. This hypothetical case merely serves to show how Accounting For Growth tackles the issue of equitable wage. In order that the hypothetical case is not confounded by other variables, we shall assume that all other variables in our CES input structure equation remain constant except for the wage distribution within the company. In other words we vary the labour input structure. 
We imagine that there are only two categories of employees, low wage workers and high wage workers. And we imagine that under the current situation, i.e. under the current wage distribution, $70 \%$ of employees belong to low wage category and these workers receive, in aggregate, $50 \%$ of the company's total wage expenses, which is $£ 1,246.7$ million. That is, their average wage is about $£ 15,121$ per year. That means $30 \%$ of employees, belonging to the high wage category, appropriates the other $50 \%$ of the wage expenses. Their average wage is about $£ 35,281$. The wage gap between low and high wage workers is $£ 20,161$. That is our hypothetical "as-is" scenario for 2016.

Notice that now we have to split the labour input $\mathbf{L}$ into two inputs, one representing low wage workers, $\mathbf{L}$, and another representing high wage workers, $\mathbf{H}$. And the corresponding returns to labour are split into $\mathbf{l}$ and $\mathbf{h}$. So our CES input structure equation has to be modified.

$\mathbf{R}=\mathbf{a} \times\left(\mathbf{m M}^{s-1 / s}+\mathbf{l L}^{\mathrm{s}-1 / \mathrm{s}}+\mathbf{h H}^{\mathrm{s-1} / \mathrm{s}}+\mathbf{k K}^{\mathrm{s-1} / \mathrm{s}}+\mathrm{gG}^{\mathrm{s}-1 / \mathrm{s}}\right)^{\mathrm{s} / \mathrm{s}-1}$

Next we ask, what if the wage gap between the low wage and the high wage categories were $£ 8,820$ instead of $£ 20,161$ ? That is, what if the wage gap were narrower? We can simulate this by assuming that $60 \%$ (instead of $70 \%$ ) of the workers received $50 \%$ of the company's total wage expenses, which we assume remained at $£ 1,246.7$ million. In other words, what if the average wage of the low wage workers were $£ 17,642$ (instead of $£ 15,121$ ) and the average wage of the high wage workers were $£ 26,461$ (instead of $£ 35,21)$.

Let's call the "as-is" scenario where $70 \%$ of employees received $50 \%$ of the total wage expenses as the 70\%:50\% wage distribution. And we call the "what-if" scenario where $60 \%$ received $50 \%$ of the total wage expenses as the $60 \%: 50 \%$ wage distribution. Clearly the 60\%:50\% wage distribution is a narrower wage gap.

The CES input structure equation for the $60 \%: 50 \%$ wage distribution is $\mathbf{R}=\left(0.685 \times 1.0110^{\mathrm{s}-1 / \mathrm{s}}+0.058 \times 0.8542^{\mathrm{s}-1 / \mathrm{s}}+0.058 \times 1.3288^{\mathrm{s}-1 / \mathrm{s}}+0.116 \times 1.0358^{\mathrm{s}-1 / \mathrm{s}}+0.082 \times 1.0524^{\mathrm{s}-1 / \mathrm{s}}\right)^{\mathrm{s} / \mathrm{s}-1}$

We plot the CES growth curves of the two wage distributions in Fig 15, with the growth potential, $\mathbf{R}$, as the horizontal axis and inter-changeability, $\mathbf{s}$, as the vertical axis. A company that operates along the curve of higher inter-changeability is able to generate greater returns to all stakeholders than one that operates along the curve with lower inter-changeability. So does Fig 15 support the general consensus that wage gap should be narrower? It turns out that the answer to our question is more nuanced than what we had assumed.

We note in Fig 15 that when the growth potential is low or negative, and the interchangeability is correspondingly low, the wage distribution should be tighter, i.e. the wage gap should be narrower. So in that case the wage distribution where $60 \%$ employees receive $50 \%$ of the company's total wage expenses is the recommended wage structure. However, as the growth potential rises, and as inter-changeability increases, wage gap should widen, and the wage distribution where $70 \%$ of employees receive $50 \%$ of the total wage expenses is recommended.

Now we consider a converse hypothetical case. We continue to imagine that under the current situation, i.e. under the current wage distribution, $70 \%$ of employees belong to low wage category and these workers receive, in aggregate, $50 \%$ of the company's total wage expenses, which is $£ 1,246.7$ million. That is, their average wage is about $£ 15,121$ 
per year. That means $30 \%$ of employees, belonging to the high wage category, appropriates the other $50 \%$ of the wage expenses. Their average wage is about $£ 35,281$. The wage gap between low and high wage workers is $£ 20,161$. That is the hypothetical "as-is" scenario for 2016.

Next we ask, what if $80 \%$ (instead of $70 \%$ ) of the workers received $50 \%$ of the company's total wage expenses, which we assume remained at $£ 1,246.7$ million. In other words, what if the average wage of the low wage workers were $£ 13,231$ (instead of $£ 15,121$ ) and the average wage of the high wage workers were $£ 52,922$ (instead of $£ 35,21)$. The wage gap is $£ 39,692$. Clearly the $80 \%: 50 \%$ wage distribution represents a wider wage gap than the 70\%:50\% wage distribution.

We plot the CES growth curves of the two wage distributions in Fig 16, with the growth potential, $\mathbf{R}$, as the horizontal axis and inter-changeability, $\mathbf{s}$, as the vertical axis. A company that operates along the curve with greater inter-changeability is able to generate greater returns to all stakeholders than one that operates along the curve with lower inter-changeability.

In Fig 16, we note that an 80\%:50\% wage distribution is almost entirely within the negative growth section of the chart. We interpret this to mean that an 80\%:50\% wage distribution is supported only when the growth potential is negative. And since the 80\%:50\% wage distribution is above the $70 \%: 50 \%$ distribtuion we conclude that when there is no potential for the company to grow, the company should not operate with a wide wage gap.
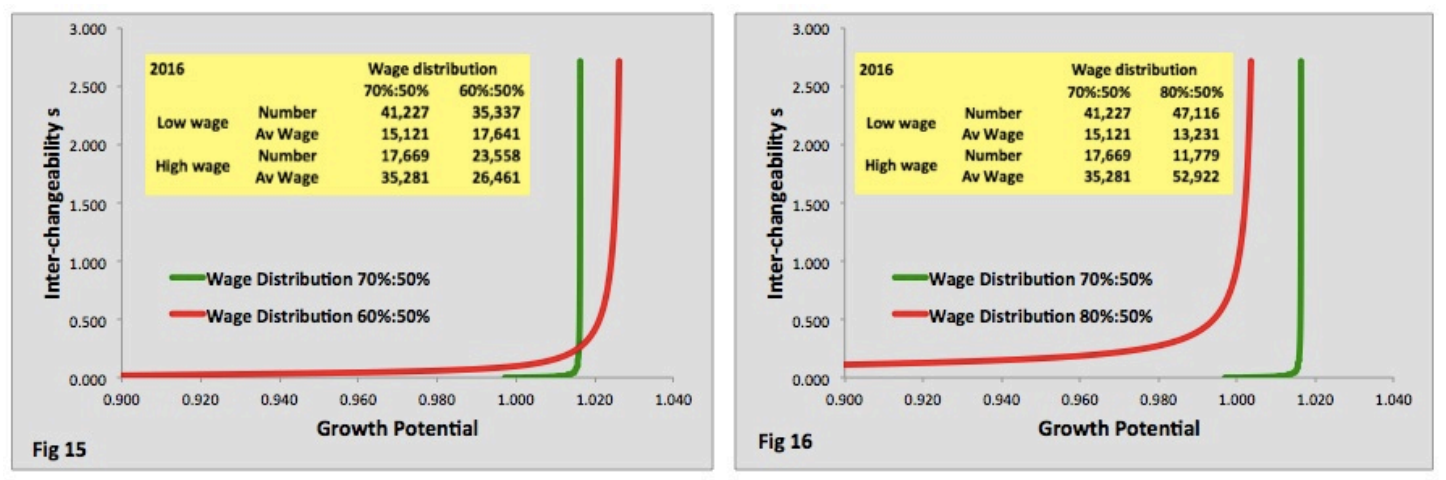

\section{Optimising Input Structure}

Compared to the performance in 2016, revenue plus VAT for 2017 grew by only $0.66 \%$, i.e., $\mathbf{R}$, was 1.0066. And $\mathbf{M}$ was 1.0098 , $\mathbf{L}$ was 1.0148 , $\mathbf{K}$ was 1.0176 and $\mathbf{G}$ was 0.9938 . Notice that consumption of public goods decreased by $0.62 \%$. Bearing in mind the Leontief equation, we know that the inter-chageability index, $\mathbf{s}$, will be greater than zero. By how much?

Fig 17 plots the CES growth curve for the 2017 input structure. Notice that the maximum expected growth is $0.99 \%$, greater than the 2017 actual growth of $0.66 \%$. That means that the growth in revenue, and its corresponding VAT, in 2017 fell short of what could have been possible, given the increase in the input structure. The green marker in Fig 17 marks the position of the the inter-changeability index, $\mathbf{s}$, along the CES growth curve for 2017. Notice that the inter-changeability index, $\mathbf{s}$, at 0.007 , is close to the lowest end of the scale. In other words, given those increases in inputs, Fig 17 shows that revenue plus VAT had the theoretical potential to, but did not, grow by $0.99 \%$. 
If M\&S had operated at inter-changeability, s, at 3.0 in 2017, growth would have been close to the maximum, at $0.98 \%$. That is, revenue plus VAT would have risen by $0.98 \%$, which would translate to higher aggregate returns to stakeholders. Revenue alone (i.e. without the VAT component, which although collected by M\&S accrues to the government) would have been $£ 34$ million higher than the 2017 actual revenue (i.e. revenue would have grown by about $£ 101$ million instead of $£ 67$ million). Profit after corporate tax could have been about $£ 63$ million higher. Tax collection would have been higher by about $£ 37$ million. And wages would have grown by $£ 25$ million. These numbers are ballpark figures because they are derived using the limited information that is available in the reported financial statements. In other words the projected numbers would be slightly more, or slightly less, if Accounting For Growth analysis were performed using the company's internal data.

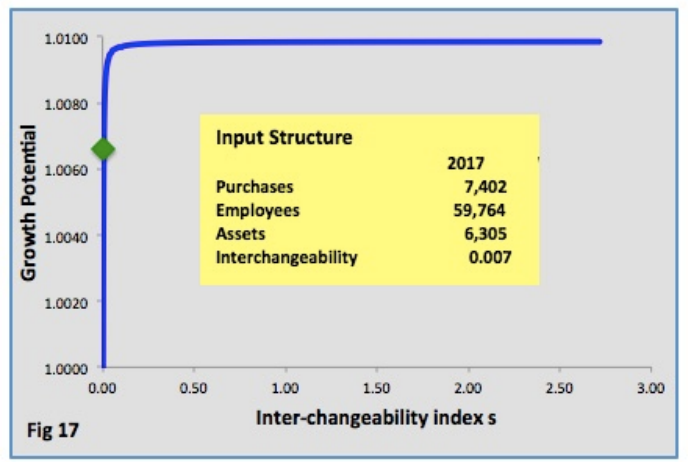

It does not mean, however, that revenue in 2017 actually could have grown by $£ 101$ million. Market conditions might have precluded a higher growth. If indeed there was little room for revenue to grow in 2017, then Fig 17 tells us that those inputs had changed in the wrong direction; that input growths should have been more modest.

So, a person reviewing the 2017 performance might ask: What should have been an input structure, given that revenue plus VAT could rise by only $0.66 \%$ ? Intuitively, we expect that there can be many different combinations of $\mathbf{M}, \mathbf{L}, \mathbf{K}$ and $\mathbf{G}$ (bear in mind that $\mathbf{G}$ is measured using value-added as proxy) that could have given us a growth of $0.66 \%$.

There is of course a very obvious combination that would result in $0.66 \%$ growth. Returning to Fig 8, we note that under uniform proportionality when all the inputs (and returns) were to increase by exactly $0.66 \%$, then growth would be be $0.66 \%$. In that case, aggregate inputs (and returns) would have increased by $0.66 \%$ (and multifactor productivity, a, would have been 1.0). But this is not the answer we are seeking.

What we are seeking is the combination of input of resources that represents a smaller aggregate increase of the input structure needed to achieve the $0.66 \%$ growth in revenue plus VAT. Such a combination of inputs would have resulted in the growth taking place at a higher end of the interchangeability index (i.e. $\mathbf{s}$ that is greater than 0.007 of Fig 17).

Fig 18 shows five different input structures that would have produced equivalent positions (i.e. the same value for $\mathbf{s}$ ) along the 2017 CES growth curve. 


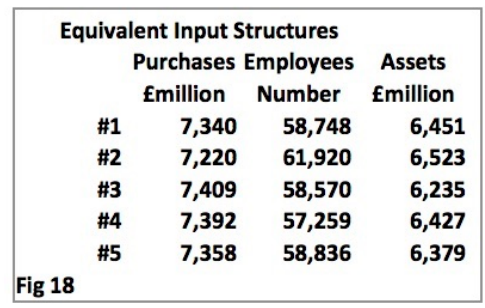

We are interested in determining if these input structures represent an improvement to the actual 2017 input structure. Recall that for a given revenue growth, i.e. $0.66 \%$ in the case of 2017, if the inter-changeability, s, is higher, the company is generating its growth with less resources. And if we plot both the What If growth curve and the actual 2017 growth curve with inter-changeability, $\mathbf{s}$, on the $y$-axis, and potential growth, $\mathbf{R}$, on the $x^{-}$ axis, the curve that belongs to an input structure with higher inter-changeability would be above (i.e. to the left of) the curve with lower inter-changeability.

Fig 19 compares the actual 2017 growth curve with the \#5 input structure of Fig 18. We denote the \#5 input structure as the What If input structure. Notice that the curve of the What If input structure lies to the left of the actual 2017 curve. We conclude that the What If input structure represents a higher inter-changeability, i.e. a larger value for $\mathbf{s}$. But by how much?

To answer that, in Fig 20 we again plot the CES growth curve for the \#5 input structure, but this time in its usual orientation, with the expected growth on the y-axis and the inter-changeability, $\mathbf{s}$, on the $x$-axis. And we note that at the expected growth of $0.66 \%$ (i.e. $\mathbf{R}=1.0066$ ), the inter-changeability, $\mathbf{s}$, is 0.5 . Compare that with Fig 17 , where the actual inter-changeability, $\mathbf{s}$, for 2017 was near zero, at 0.007 .
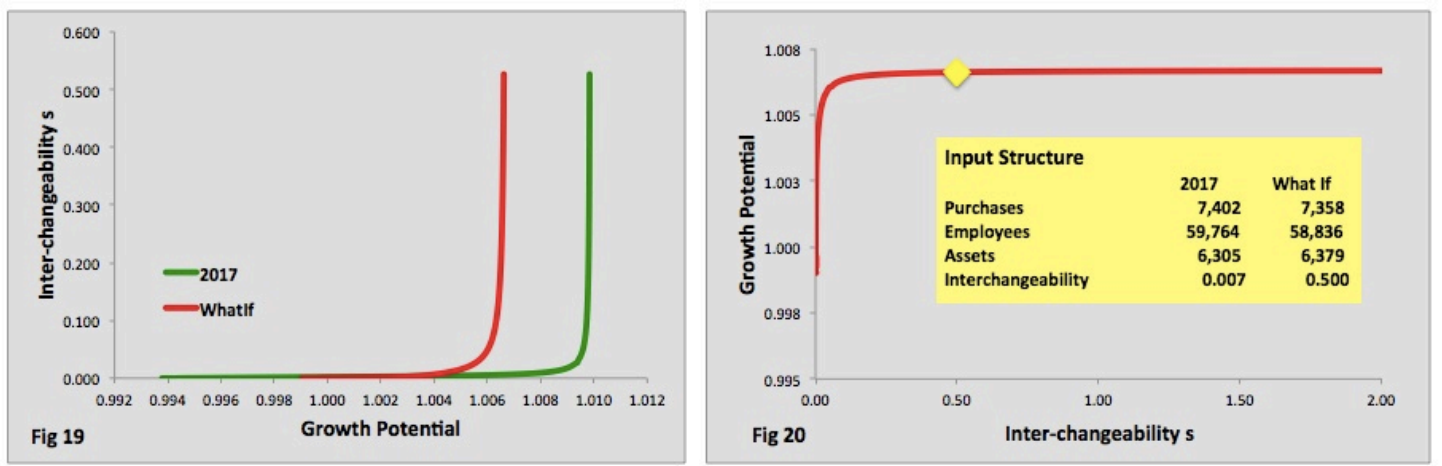

Next we repeat this exercise with another input structure of even greater interchangeability. And in so doing we will show that Accounting For Growth is indeed a finely graduated measuring tool.

Fig 21 is another set of five input structures that would have produced equivalent positions along the 2017 growth curve.

\begin{tabular}{|c|c|c|c|}
\hline \multicolumn{3}{|c|}{$\begin{array}{l}\text { Equivalent Input Structures } \\
\text { Purchases Employees }\end{array}$} & \multirow{2}{*}{$\begin{array}{l}\text { Assets } \\
\text { fmillion }\end{array}$} \\
\hline & fmillion & Number & \\
\hline$\# 6$ & 7,483 & 57,601 & 6,067 \\
\hline$\# 7$ & 7,453 & 59,219 & 6,003 \\
\hline$\# 8$ & 7,325 & 58,782 & 6,483 \\
\hline$\# 9$ & 7,383 & 56,956 & 6,475 \\
\hline$\# 10$ & 7,493 & 57,315 & 6,035 \\
\hline Fig 21 & & & \\
\hline
\end{tabular}


The five input structures of course are equivalent only in the aggregate. That is, these different input structures have exactly the same CES growth curve. But the contributions by the different types of stakeholders are different. And if we plot the CES growth curves for these five input structures, we should find that the actual 2017 growth in revenue plus VAT (at $0.66 \%$ ) falls in exactly the same position on all the curves.

However, because the contributions by the different stakeholders are different between these different input structures, the returns to the each class of stakeholders also would be different between the different input structures. A review of Fig 22 would make this point clear.

So which input structure would a company choose? It depends. A social enterprise might try to maximise returns to society. A company that is sensitive to shareholders' activism might try to maximise returns to shareholders. A company that practises Rita no Kokoro might try to preserve, or even maximise employees' income, while keeping an eye that it does not alienate other stakeholders. But all companies, while selecting the input structure that best reflects its ethos, would at the same time strive to maximise the aggregate returns to stakeholders by maximising the inter-changeability index, $\mathbf{s}$. For this exercise, we will use input structure \#8.

\begin{tabular}{|c|c|c|c|c|c|}
\hline \multicolumn{6}{|c|}{ Returns To Stakeholders } \\
\hline & \multirow{2}{*}{$\begin{array}{l}\text { Suppliers } \\
\text { fmillion }\end{array}$} & \multirow{2}{*}{$\begin{array}{l}\text { Employees } \\
\text { Emillion }\end{array}$} & \multicolumn{2}{|c|}{ s Sharehold Creditors } & \multirow{2}{*}{$\begin{array}{l}\text { Society } \\
\text { fmillion }\end{array}$} \\
\hline & & & Emillion & fmillion & \\
\hline 2017 & 7,402 & 1,297 & 492 & 77 & 915 \\
\hline \#6 & 7,483 & 1,250 & 490 & 74 & 873 \\
\hline$\# 7$ & 7,453 & 1,285 & 486 & 73 & 878 \\
\hline \#8 & 7,325 & 1,276 & 560 & 79 & 891 \\
\hline$\# 9$ & 7,383 & 1,236 & 551 & 79 & 883 \\
\hline$\# 10$ & 7,493 & 1,244 & 490 & 73 & 872 \\
\hline Fig 22 & & & & & \\
\hline
\end{tabular}

Fig 23 compares the growth curve of the actual 2017 input structure with the curve for the \#8 input structure of Fig 21. Notice that the What If curve lies to the left of the actual 2017 curve. We conclude that the \#8 input structure consumes less resources in aggregate than the actual 2016 input structure. But can we compare the \#8 input structure with the \#5 input structure? Can we say with precision which input structure represents the smaller aggregate input resources?

To answer that, in Fig 24 we again plot the curve for \#8 input structure in its usual orientation, with the potential growth on the $y$-axis and the inter-changeability, $\mathbf{s}$, on the $\mathrm{x}$-axis. And we note that at the potential growth of $0.66 \%$ (i.e. $\mathbf{R}=1.0066$ ), the interchangeability, s, denoted by a green marker, now is 2.0. Recall that in Fig 20 we determined that the inter-changeability, $\mathbf{s}$, for input structure \#5 was 0.5 , and that in Fig 17, we determined that the actual inter-changeability, $\mathbf{s}$, for 2017 was near zero, at 0.007 .

So Accounting For Growth indeed provides us with a finely graduated metric to distinguish between these different input structures.

In the next section, we will consider how Fig 17 and Fig 24 also provide us with a clearer insight into the meaning of the inter-changeability index, $\mathbf{s}$. 

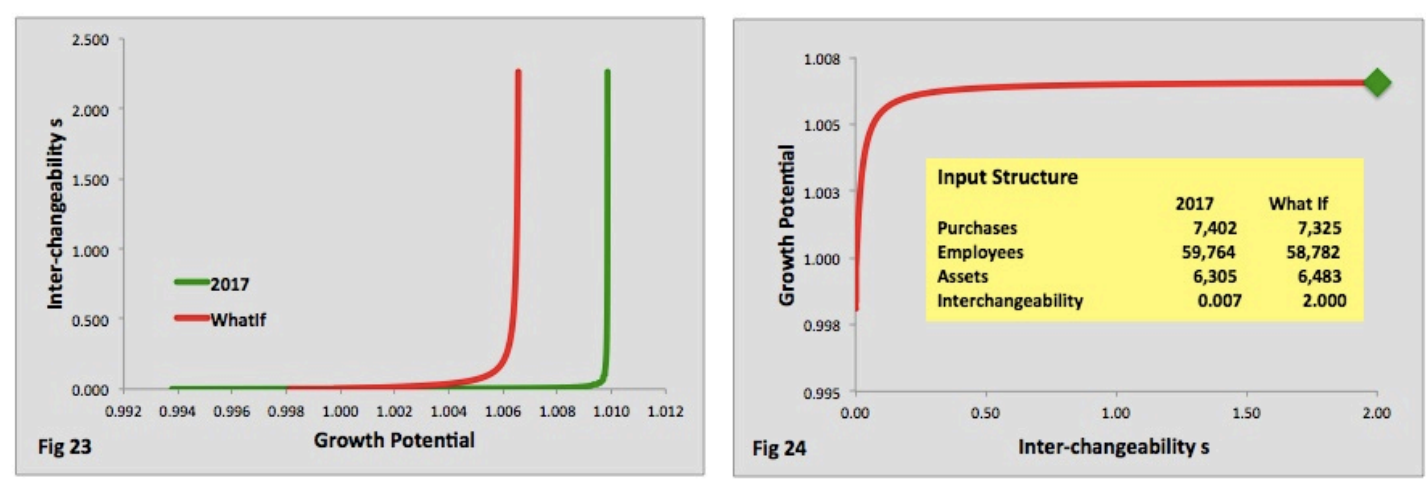

\section{The Inter-changeability Index}

Let's re-examine Fig 17, which is reproduced below as Fig 25. That is, Fig 25 plots the CES growth curve for the 2017 input structure. Notice that the maximum expected growth is $0.99 \%$, greater than the 2017 actual growth of $0.66 \%$. That means that the growth in revenue, and its corresponding VAT, in 2017 fell short of what could have been possible, given the increase in the input structure. The green marker in Fig 25 marks the position of the the inter-changeability index, $\mathbf{s}$, along the CES growth curve for 2017. Notice that the inter-changeability index, $\mathbf{s}$, at 0.007 , is close to the lowest end of the scale. In other words, given those increases in inputs, Fig 25 shows that revenue plus VAT had the theoretical potential to, but did not, grow by $0.99 \%$.

Now compare Fig 25 with Fig 26, which repeats the CES growth curve for the 2017 input structure but also incorporates the CES growth curve of Fig 24. That is, Fig 26 has two growth curves, one representing the actual 2017 input structure, the other representing a smaller aggregate input structure. Notice that the company could replicate a growth of $0.66 \%$ using the smaller aggregate input structure if the company could operate at a higher inter-changeability index, $\mathbf{s}$, of 2.0 instead of operating at an inter-changeability of 0.007 .

So for a given set of input structure, revenue growth (and the corresponding VAT growth) is higher when the value of inter-changeability, $\mathbf{s}$, is larger. Conversely, for a given revenue growth, if the inter-changeability, $\mathbf{s}$, is high, the company is generating its growth with less resources.


\section{Concluding Remarks}

Pay inequality, tax avoidance, abuse of superior bargaining power, climate-change... the list of corporate misdeeds seems to keep growing. No company wants to be labelled as being guilty of any of these practices. Some mention of corporate social responsibility has become de rigueur in corporate annual reports. But short of making high sounding 
declarations how can a company show that its practices have been fair and socially responsible?

This article started with the premise that society, employees, suppliers, creditors and shareholders have a collective stake in the wellbeing of the company, and that the company's performance should be judged by its returns to all stakeholders. The returns to each class of stakeholders should be commensurate with their contributions. This view contrasts with the usual shareholder centric measurements of corporate performance.

Traditional metrics might provide the answers sought by one or another class of stakeholders, but they do not address the question of whether the maximisation of returns to one class of stakeholders might be at the expense of another.

Accounting For Growth offers a comprehensive metric that measures whether a company's growth in revenue has been achieved through an efficient combination of the contributions by, and the equitable returns to, all its stakeholders.

This article demonstrated that it is feasible, by using information that is available in a corporation's annual report, and in particular information in its financial statements, to measure corporate performance that maximises returns to all stakeholders. And if the same revenue plus VAT could be had for less inputs, that translates to higher returns to all stakeholders.

\section{References}

Arrow, K., Chenery, H., Minhas, B., \& Solow, R. (1961). Capital-Labor Substitution and Economic Efficiency. The Review of Economics and Statistics, 43(3), 225-250. doi:10.2307/1927286

CSONTOS, L., \& RAY, S. (1992). The Leontief Production Function as a Limiting Case of the CES. Indian Economic Review,27(2), new series, 235-237

Douglas, P. (1976). The Cobb-Douglas Production Function Once Again: Its History, Its Testing, and Some New Empirical Values. Journal of Political Economy, 84(5), 903-915

Inamori, K. (2015), Lecture given by Dr. Kazuo Inamori: The Significance of Rita no Kokoro for Business Administration [Transcript], Retrieved from http://www.ritsumei.ac.jp/research/riprc/common/eng/file/news/20151001_Lecture.pdf

Marks And Spencer. (2015). 2015 annual report of Marks And Spencer Group PLC. Retrieved from http://annualreport2015.marksandspencer.com

Marks And Spencer. (2016). 2016 annual report of Marks And Spencer Group PLC. Retrieved from http://annualreport2016.marksandspencer.com

Marks And Spencer. (2017). 2017 annual report of Marks And Spencer Group PLC. Retrieved from http://annualreport2017.marksandspencer.com

Morley, M. (1979). The Value Added Statement in Britain. The Accounting Review, 54(3), 618-629

Smith, V. (1969). The CES Production Function: A Derivation. The American Economist, 13(1), 72 76 